\title{
AVALIAÇÃo FITOQUímICA E MICROBIOLÓGICA DA ESPÉCIE Artemisia annua L., SUBMETIDA A TRATAMENTOS DE ARMAZENAMENTO E CONDIÇÕES DE AMBIENTE
}

\author{
Thalita Cristina Marques Cervezan ${ }^{1}$, Fernando Broetto ${ }^{2}$, Glyn Mara Figueira ${ }^{3}$, Aline \\ Cristina Rabonato ${ }^{4}$ \& Ilza Maria de Oliveira Souza ${ }^{5}$
}

RESUMO: A espécie Artemisia annua, Asteraceae, nativa da China, tem a artemisinina como seu principal componente ativo, é considerado um potente antimalárico. Com o aumento do valor dos princípios ativos naturais, estudos relacionados à pós-colheita e armazenamento de material vegetal tornam-se importantes para melhor conservação de suas propriedades fitoterápicas. O presente estudo teve como objetivo definir as melhores condições de armazenamento para preservar a qualidade da droga vegetal. Folhas de A. annua secas foram armazenadas por seis meses em sacos de polietileno envolto por papel Kraft e acondicionadas em quatro tratamentos: em condição ambiente e refrigerada a $4^{\circ} \pm 2 \mathrm{C}$, em embalagem normal e em embalagem sob vácuo. No tempo zero e nos períodos de 30, 90,120 e 180 dias foram realizados as análises microbiológicas, de teor de umidade e de avaliação do teor de artemisinina. Os resultados dos ensaios microbiológicos não demonstraram contaminação significante, assim como o teor de umidade do material armazenado, que permanece entre 5\% a 10\%, mantendo-se dentro do parâmetro aceitável. O tratamento sem vácuo ambiente (SVA) foi o que melhor manteve estabilidade de armazenamento durante os 180 dias, no entanto, foi o sem vácuo refrigerado (SVR) que apresentou maior eficiência para a conservação do teor de artemisinina.

PALAVRAS-CHAVE: princípio ativo, artemisinina, plantas medicinais.

\section{PHYTOCHEMICAL AND MICROBIOLOGICAL EVALUATION OF THE SPECIES Artemisia annua L. SUBMITTED TO TREATMENT STORAGE AND CONDITIONS OF AMBIENT}

\begin{abstract}
The species Artemisia annua L. (Asteraceae) is native to China and has artemisinin as its main active component, substance that is considered a potent antimalarial drug. With the increased interest in natural active principles, studies related to post-harvest and storage of vegetable material become important for better conservation of its phytotherapic properties. Therefore, the present study had as objectivedefine the best storage conditions to preserve and keep the quality of phytotherapic drugs. Leaves of $A$. annua dried were stored for six months in polyethylene bags wrapped in Kraft paper and packed in four treatments: at ambient condition, refrigerated at $4 \pm 2$ oC, using normal packing, and using vacuum packing. Samples were taken for microbiological, moisture content, and level of artemisinin analyses before the experiment begun and at 30, 90, 120 and 180 days. The results of microbiological tests showed no significant contamination, as well as the moisture content of the stored (biological) material, which remain between 5\% and $10 \%$, keeping within acceptable parameters. The ambient without vacuum treatment (SVA) was the treatment that better maintained the sample stability during 180 days, however, the refrigerated without vacuum (SVR) showed greater efficiency to conserve the content of artemisinin.
\end{abstract}

KEYWORDS: active principle, artemisinin, medicinal plants.

\footnotetext{
1 Doutoranda da FCA/UNESP. Programa Energia na Agricultura.

E-mail: thacmc@yahoo.com.br

${ }^{2}$ IBB/UNESP. E-mail: broetto@ibb.unesp.br

${ }^{3}$ CPQBA/UNICAMP. E-mail: glyn@cpqba.unicamp.br

${ }^{4}$ CPQBA/UNICAMP. E-mail: alinerabonato@yahoo.com.br

${ }^{5}$ CPQBA/UNICAMP. E-mail: ilza@cpqba.unicamp.br
} 


\section{INTRODUÇÃO}

A utilização e comercialização de plantas medicinais têm estimulado a demanda crescente na indústria pela busca de novas fontes naturais de medicamentos. O aumento desse consumo natural também é incentivado devido aos efeitos colaterais causados pelos fármacos sintéticos (VAN DEN Berg, 1993). Os medicamentos fitoterápicos apresentam duas diferenças importantes quando comparados com os sintéticos. A primeira, é que ao contrario dos medicamentos sintéticos, os princípios ativos dos fitoterápicos raramente são conhecidos. Já a segunda diferença fundamental é que o controle da qualidade e a padronização dos fitoterápicos são tarefas bem mais complexas do que no caso dos medicamentos sintéticos (CALIXTO, 2001).

À medida que estudos químicos e farmacológicos confirmam cientificamente suas ações terapêuticas, aumenta a demanda por matéria-prima envolvida na elaboração destes fitomedicamentos e a busca por produto de alta qualidade torna-se cada vez maior. Sejam estas espécies provenientes do extrativismo ou do cultivo, o material vegetal produzido deve passar pelo processo de secagem e armazenamento a fim de atender às exigências do mercado (Figueira et al. 2004).

Várias espécies medicinais e/ou aromáticas têm sido alvo de estudo quanto à produção e composição de seus princípios ativos. Devido ao seu efeito antimalárico a Artemisia annua tem se tornado cada vez mais importante, assim como a sua comercialização. Esta espécie produz lactona sesquiterpênica, a artemisinina, muito ativa no tratamento da malária falciparum.

O Relatório Mundial da Malária de 2012 resume os dados recebidos de 104 países com paludismo endémico e territórios para 2011. Noventa e nove desses países tinham em curso a transmissão da malária. Segundo as últimas estimativas da Organização Mundial da Saúde OMS havia cerca de 219 milhões de casos de malária em 2010 e estima 660.000 mortes. A África é o continente mais afetado: cerca de $90 \%$ de todas as mortes por malária ocorrem lá (ORGANIZAÇÃO MUNDIAL DA SAÚDE, 2013).

Entre 2000 e 2010, as taxas de mortalidade por malária caíram 26\% em todo o mundo. Segundo a OMS, a região africana apresentou uma queda de 33\%. Durante este período, cerca de 1,1 milhões de mortes de malária foram evitadas globalmente, principalmente como resultado de um aumento de escala das intervenções. No entanto, a malária continua a tirar a vida de uma criança africana a cada minuto de cada dia. A Nigéria tem uma das maiores cargas de malária no mundo. Em 2010, 489 mil casos de malária grave foram relatados, resultando em 200.000 mortes (ORGANIZAÇÃO MUNDIAL DA SAÚDE, 2011).
No Brasil, 40 milhões de pessoas estão em risco de contrair a doença. Em 2010, o país teve 334.618 casos confirmados de malária, dos quais 283.383 eram de Plasmodium vivax e 47.406 de Plasmodium falciparum (REDDY, 2013). Em 2011, registaram-se 270.000 casos confirmados e 2,6 milhões de casos suspeitos de malária (LACERDA, 2013). A Sociedade Brasileira de Medicina Tropical, criada em 1962, está envolvida na luta contra doenças tropicais infecciosas e parasitárias e é questão de fomentar a partilha de conhecimento entre pesquisadores nacionais e internacionais e parcerias público-privadas como Medicines for Malaria Venture - MMV (REDDY, 2013). Pesquisas recentes sobre condições de armazenamento estão sendo desenvolvidas para que o material vegetal mantenha ao máximo suas propriedades antimaláricas (FIGUEIRA, 1996).

A qualidade pode ser preservada através do estudo dos parâmetros de secagem e condições de armazenamento. Informações sobre a umidade de equilíbrio de drogas vegetais tornam-se cada vez mais significantes, pois definem as condições mais adequadas de armazenamento deste material. Neste contexto, a secagem e o armazenamento inadequado podem prejudicar as características físico-químicas, biológicas e a qualidade das plantas afetando principalmente o fitoterápico (SILVA, 2005). Buscar técnicas que proporcionem a preservação da qualidade da droga vegetal no período pós-colheita, principalmente através de condições de armazenamento foi o objetivo principal deste trabalho.

\section{MATERIAL E MÉTODOS}

F A espécie de $A$. annua em estudo foi cultivada no campo experimental do Centro Pluridisciplinar de Pesquisas Químicas, Biológicas e Agrícolas (CPQBA) da Universidade Estadual de Campinas (Unicamp), localizada em Paulínia, SP.

A matéria fresca (folhas e hastes) foi coletada no inicio de março em 2012, antes do florescimento, período em que a concentração de artemisinina é maior, sendo posteriormente submetida ao processamento de limpeza, secagem e armazenamento.

As folhas recém-colhidas passaram por processo de limpeza retirando impurezas e galhos, sendo submetidas à secagem em estufa com circulação de ar a temperatura de $\pm 40^{\circ} \mathrm{C}$, até que a massa de matéria seca se mantivesse constante. Após a secagem, o material vegetal foi submetido a armazenamento em sacos de polietileno envoltos de papel Kraft, visando reproduzir a mesma embalagem utilizada pela maioria dos produtores de plantas medicinais e aromáticas.

Primeiramente, para cada tratamento, foram pesadas cerca de $40 \mathrm{~g}$ de folhas secas moídas e acondicionadas nas embalagens de polietileno com quatro repetições. As embalagens foram seladas em Seladora com sistema de 
vácuo e, posteriormente envolvidas em papel Kraft. As folhas secas embaladas foram submetidas aos quatro tipos de armazenamento:

- Condições de vácuo (0,1 atm) em temperatura ambiente de $25^{\circ} \pm 3$

- Condições sem vácuo em temperatura ambiente de $25^{\circ} \pm 3$;

- Condições de vácuo (0,1 atm) em temperatura refrigerada de $4^{\circ} \pm 2$

- Condições sem vácuo em temperatura refrigerada de $4^{\circ} \pm 2$;

As embalagens submetidas às condições ambientes foram armazenadas em prateleiras dentro de armário de madeira com portas, mantendo o ambiente livre de contato externo e ao abrigo de luz. Embalagens em condições refrigeradas foram armazenadas em geladeira em prateleiras de vidro. Em ambas as condições, as amostras não tiveram em contato com qualquer outro produto ou amostras de diferentes espécies. Foi utilizado termômetro digital para monitorar a temperatura dos ambientes.

Ao completar os tempos de 30, 90, 120 e 180 dias de armazenamento as amostras respectivas destes períodos eram acondicionadas em freezer $-20^{\circ} \mathrm{C}$, preservando o estado microbiológico e químico. Ao final do armazenamento as amostras foram retiradas do freezer e descongeladas para as subsequentes análises.

O congelamento comum se baseia na conservação adequada de agentes em temperaturas relativamente baixas entre $-4^{\circ} \mathrm{C}$ e $-20^{\circ} \mathrm{C}$. O método de congelamento oferece segurança para o material armazenado evitando o desenvolvimento de diversos microrganismos por períodos de 3 meses a 2 anos, devido a uma redução significativa no metabolismo celular (SOLA et al., 2012).

O material vegetal armazenado no tempo inicial (após a secagem das folhas) e aos 30, 90 e 180 dias foi avaliado quanto à atividade microbiológica, teor de umidade e quantificação do principio ativo. As amostras armazenadas por 120 dias foram submetidas somente para a avaliação do teor de umidade e teor de artemisinina devido à estabilidade e microbiológica nos períodos de 90 e 180 dias.

O teor de umidade de um produto é a proporção entre a quantidade de água (em massa) existente no material e a massa seca (que não contém água, ou seja, sólidos totais como proteínas, cinzas, etc.). A determinação do teor de umidade é a quantidade de água que pode ser removida do material sem alteração da estrutura molecular do sólido (SILVA, 2005).
A determinação do teor de umidade das amostras foi realizada no final do período de 180 dias de armazenamento. As amostras foram retiradas do freezer e descongeladas; cerca de +/- $1 \mathrm{~g}$ de todas as amostras foram pesadas em balança digital analítica em triplicada e colocadas em cadinhos de alumínio. A massa seca foi determinada colocando os cadinhos em estufa com circulação forçada a $105^{\circ} \mathrm{C}$ por $24 \mathrm{hrs}$. Após este período os cadinhos foram retirados, pesados e quantificados (FARMACOPÉIA BRASILEIRA, 1988).

Após os tempos de 30, 90 e 180 dias (incluindo o tempo zero), coletou-se $10 \mathrm{~g}$ do material vegetal que foi congelado, para posterior análise microbiológica. As análises microbiológicas foram feitas na Fundação André Tosello, utilizando metodologias propostas pela Farmacopeia Brasileira 50 - Edição - 2010. Os parâmetros microbiológicos avaliados foram: Contagem Padrão de Bactérias Heterotróficas, Contagem total de Fungos (Bolores e Leveduras), Microrganismos viáveis Totais (Fungos e Bactérias), Coliformes Totais e Coliformes Termotolerantes/ Escherichia coli.

A avaliação cromatográfica foi realizada no Departamento de Fitoquímica do CPQBA/ UNICAMP, em Paulínia - SP. Realizou-se uma quantificação semianalítica comparativa do teor de artemisinina utilizando a técnica de Cromatografia em Camada Delgada com detecção por Densitometria (MARCHESE et al., 2001).

Para cada amostra, foram retirados, em triplicatas, $1 \mathrm{~g}$ de folhas finamente moídas, extraídas em $5 \mathrm{~mL}$ de diclorometano. Posteriormente, o extrato foi levado a uma mesa agitadora por uma hora e meia, sendo subsequentemente filtrado. Esse procedimento foi repetido por 3 vezes, tendo o volume líquido total obtido avolumado em balão de $10 \mathrm{~mL}$.

Com auxílio de microseringa, $10 \mu \mathrm{L}$ de cada extrato foi aplicado sobre placa de sílica-gel. Cada placa recebeu seis diferentes concentrações do padrão artemisinina $(2,0 ; 4,0 ; 6,0 ; 8,0 ; 10,0$ e $12,0 \mu \mathrm{g})$ ao centro, mais 6 aplicações laterais, em triplicatas, das amostras. As placas do ensaio foram eluídas em cuba de vidro previamente saturada com uma mistura de diclorometano : metanol $(98,5: 1,50)$. Para a revelação, utilizou-se uma solução contendo $50 \mathrm{~mL}$ de ácido acético glacial, 0,5 mL de anisaldeído e 1,0 mL ácido sulfúrico concentrado, a qual foi borrifada sobre as placas.

Posteriormente, cada placa foi colocada em estufa a $110^{\circ} \mathrm{C}$ durante 5 minutos. Em seguida as placas foram escaneadas para avaliação densitométrica sendo que a área do composto foi avaliada por comparação com a área dos picos dos padrões com os das amostras. Os resultados obtidos foram submetidos ao programa SAEG (Sistemas de Análises Estatísticas e Genéticas) em teste de Tukey com nível de significância de $5 \%$ de probabilidade. O teor da artemisinina em relação ao 
tempo de armazenamento foi avaliado pela análise de regressão (Figura 2).

\section{RESULTADOS E DISCUSSÃO}

Os resultados obtidos (Tabela 1) nos ensaios microbiológicos indicam que não há contaminação significante em relação aos parâmetros estabelecidos pela Farmacopeia Brasileira 5 Edição - 2010.

Tabela 1: Avaliação microbiológica de bactérias heterotróficas dos tratamentos em relação aos dias de armazenamento.

Contagem Padrão de Bactérias Heterotróficas

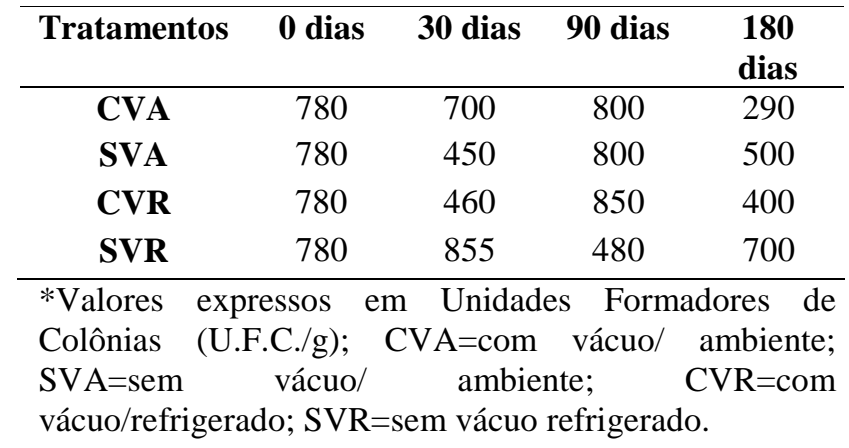

As amostras também foram avaliadas quanto à contagem total de fungos (bolores e leveduras) e microrganismos totais viáveis (fungos e bactérias), porém não foram determinados valores expressivos. Os valores encontrados foram inferiores ao da especificação a qual estabelece como ideal $<5700$ U.F.C./g. As demais análises comprovaram ausência de coliformes totais, coliformes termotolerantes e Escherichia coli.

Alguns trabalhos da literatura avaliaram o armazenamento de material vegetal em embalagens e temperaturas variadas. Os resultados apresentados por esses autores foram distintos aos comparados com esse presente trabalho.

Fidelis et al. (2005) avaliaram o armazenamento de Sphagneticola trilobata em embalagens de vidro, polipropileno e papel metalizado por período de 12 meses, sob condição ambiente $\left(20-25^{\circ} \mathrm{C}\right)$ e refrigerado $\left(5^{\circ} \mathrm{C}\right)$. Segundo os autores, a quantificação de fungos filamentosos e leveduras apresentaram variações significativas, constatando que, em condições refrigeradas, independente da embalagem ou período de armazenamento, apresentaram valores maiores de microrganismo do que a condição ambiente. Também houve presença de Staphylococcus spp. em todas as condições de armazenamento, independente do tipo de embalagem. Em média, o aumento destes microrganismos foi de dez vezes no armazenamento em condições ambientes e de cem vezes sob-refrigeração. Para o microrganismo Staphylococcus aureus, pode-se estimar que o número encontrado nas amostras, independente da condição e do período de armazenamento, estava abaixo de 102 U.F.C./g. A Tabela 1 descrita anteriormente demonstra ausência de coliformes totais nas amostras armazenadas de artemisinina, independe dos tratamentos. Já para Fidelis et al. (2005) houve presença desse microrganismo em todos os produtos de embalagens refrigeradas após o período de incubação. Também foi detectada presença para bactérias aeróbicas mesófilas em produtos de condição ambiente, independente da embalagem, com 105 U.F.C./g e sob-refrigeração para embalagens de vidro e papel metalizado, com valor máximo de 106 U.F.C./g.

Alguns autores ressaltam a possibilidade de que a refrigeração e/ou congelamento de amostras vegetais podem camuflar os resultados microbiológicos avaliados ao longo do armazenamento. Silva et al. (2008) propuseram avaliar a viabilidade de microrganismos presentes em uma coleção de cultura, afim de validar esse hipótese. Semearam um total de 328 leveduras dos gêneros Candida, Cryptococcuss, Trichosporon, Rodothorulla em caldo cérebrocoração contendo glicerol, mantendo-as sob-refrigeração por sete dias e posterior congelamento a $-20^{\circ} \mathrm{C}$, sob três diferentes períodos de tempo. Após três anos de congelamento, observaram recuperação de 99,0\% das leveduras (72 viáveis/73 microrganismos congelados). No segundo período (três anos e seis meses) observaram a viabilidade de $100 \%$ das cepas congeladas (96 leveduras congeladas e viáveis após o descongelamento). No último grupo, após o congelamento de 159 leveduras por quatro anos, notaram uma redução da viabilidade das culturas com 90,6\% de recuperação (144 leveduras). Diante dos resultados, observaram que o emprego de baixas temperaturas foi vantajoso por seu baixo custo, fácil execução, além de ter favorecido a conservação de quase totalidade das leveduras por 48 meses (SOLA et al., 2012).

Como dito anteriormente, o teor de umidade considerado ideal para material biológico ser armazenado é entre as faixas de $5 \%$ a $10 \%$. Conforme esta indicação pode-se dizer que as amostras, mesmo depois do congelamento, se mantiveram dentro do parâmetro (Tabela 2).

Tabela 2: Valores médios do teor de umidade das amostras ao final do processo de armazenamento.

\begin{tabular}{ccccc}
\hline Tratamentos & 30 dias & 90 dias & 120 dias & 180 dias \\
\hline CVA & 8,8966 a & $10,7572 \mathrm{a}$ & $10,6783 \mathrm{a}$ & $10,0688 \mathrm{ab}$ \\
SVA & $8,4666 \mathrm{a}$ & $9,2195 \mathrm{ab}$ & $10,6681 \mathrm{a}$ & $10,8876 \mathrm{a}$ \\
CVR & $8,1014 \mathrm{a}$ & $9,3656 \mathrm{ab}$ & $8,9950 \mathrm{a}$ & $9,4152 \mathrm{ab}$ \\
SVR & $8,8281 \mathrm{a}$ & $7,8457 \mathrm{~b}$ & $8,8217 \mathrm{a}$ & $7,7725 \mathrm{~b}$ \\
\hline CV\% & 4.26 & 8.18 & 9.22 & 12.41
\end{tabular}

As médias contendo letras distintas na coluna demonstram haver diferença significativa entre si pelo teste de Tukey de $5 \%$ de probabilidade. CVA= com 
vácuo/ambiente; $\mathrm{SVA}=$ sem vácuo/ambiente; $\mathrm{CVR}=$ com vácuo/refrigerado; SVR =sem vácuo refrigerado.

Pela análise estatística (Tabela 2), percebe-se que aos 30 dias e 120 dias não houve diferença significativa entre os tratamentos quanto aos teores de umidade. Somente houve uma diferença expressiva nos tempos de 90 dias e 180 dias, correspondentes ao tratamento de SVR que, ao contrário dos outros tratamentos, perdeu umidade.

Entre todos os tratamentos avaliados, os refrigerados adquiriram menos umidade devido ao fato que a geladeira possui uma pressão de água menor, sendo assim, um produto armazenado em um ambiente com baixa atividade de água sofre uma redução de umidade na tentativa de entrar em equilíbrio com o ambiente externo. Para comprovar essa afirmação, podem-se citar vários trabalhos científicos que demonstram perda de umidade em amostras armazenadas ao longo do tempo.

Em comparação com a Tabela 2 acima, podem-se citar Guedes et al. (2012) que propuseram armazenar sementes de Myracrodruon urundeuva em intervalos prédeterminados $(0,30,60,90,120,150,180,210$ e 240 dias) em embalagens de papel Kraft, algodão, polietileno transparente e folhas de papel alumínio, sob condições ambiente $\left(25 \pm 2^{\circ} \mathrm{C}\right)$, freezer $\left(-20 \pm 2^{\circ} \mathrm{C}\right)$, câmara fria (8 $\left.\pm 2^{\circ} \mathrm{C}\right)$ e geladeira $\left(6 \pm 2^{\circ} \mathrm{C}\right)$. Os autores avaliaram a porcentagem de emergência, índice de velocidade de emergência, comprimento, massa seca de plântulas e teor de água das sementes. Os resultados mostraram que a geladeira ou freezer é a condição mais adequada para o armazenamento das amostras, por um período de 240 dias, sob qualquer embalagem proposta pelo trabalho. Quanto ao teor de umidade, observou-se que as sementes obtiveram menor dosagem de água quando armazenados em geladeira, apresentando os percentuais de 9-11\% em embalagens de plástico e alumínio e 9-7\% para pano e papel. Em condição ambiente, as amostras em embalagem plástica mantiveram-se estáveis com 10\% de umidade durante os 240 dias, as demais sementes apresentaram uma variação de 10-11\% em alumínio e 10-13\% em papel e pano. Em câmara fria, a embalagem plástica e a de alumínio mantiveram os índices de 10$12 \%$ de umidade e para a embalagem de pano e papel apresentaram uma faixa de $11-20 \%$. As amostras acondicionadas em freezer apresentaram teores de 10$16 \%$ em alumínio, $12-14 \%$ para plástico e $11-16 \%$ para o pano e papel.

Outros autores avaliaram o armazenamento de Sphagneticola trilobata em embalagens de vidro, polipropileno e papel metalizado por período de 12 meses, sob condição ambiente $\left(20-25^{\circ} \mathrm{C}\right)$ e refrigerado $\left(5^{\circ} \mathrm{C}\right)$. O teor de umidade sob-refrigeração e acondicionadas em papel metalizado tiveram as menores variações de umidade, com variação de 8,8-10,5\%. As amostras armazenadas sob-refrigeração em polipropileno apresentaram variação de 10,1-12,2\%. Em condição ambiente, independente da embalagem, sempre esteve, em média, acima de $10 \%$, sendo os maiores valores 14,2 e 14,4 nas embalagens de vidro e papel metalizado, respectivamente (FIDELIS, et al., 2005).

Para estudar o efeito dos tratamentos e do tempo de armazenamento, foram realizadas análises de variância (Tabela 3).

Tabela 3: Efeito dos tratamentos e do tempo de armazenamento.

\begin{tabular}{cccccc}
\hline \multicolumn{6}{c}{ ANOVA } \\
\hline $\begin{array}{c}\text { Fontes de } \\
\text { Variação }\end{array}$ & G.L. & \multicolumn{5}{c}{ Quadrado Médio } \\
\hline \multicolumn{7}{c}{30} & 90 & 120 & 180 \\
& & dias & dias & dias & dias \\
\hline Tratamento & 3 & $4,06^{* *}$ & $5,04^{* *}$ & $4,28^{* *}$ & $3,28^{* *}$ \\
Resíduo & 12 & 0,24 & 0,34 & 0,14 & 0,17 \\
\hline
\end{tabular}

Houve uma variação significativa no teor de artemisinina tanto entre os tratamentos quanto ao decorrer do período de armazenamento (Figura 1).

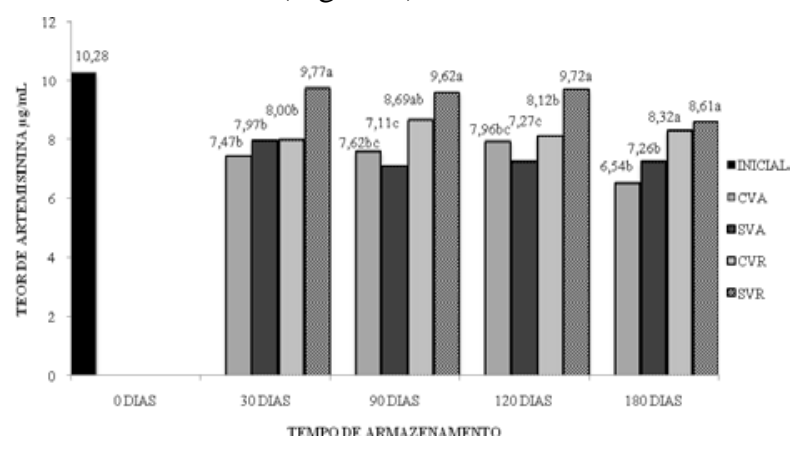

Médias seguidas da mesma letra, na coluna, não diferem entre si pelo teste de Tukey (5\%); Tratamentos, com vácuo ambiente; CVA, sem vácuo ambiente; SVA, com vácuo refrigerado; CVR, sem vácuo refrigerado; SVR.

\section{Figura 1: Teor de artemisinina em amostras de A.annua em função dos tratamentos de armazenamento durante o tempo.}

Devido à variação do teor de água nas amostras armazenadas, os resultados do teor de artemisinina foram corrigidos conforme os seus valores correspondentes na Tabela 2.

Durante os 30 primeiros dias houve uma diferença expressiva entre os tratamentos de SVR em relação aos demais. Essa característica se manteve contínua durante quase todo o tempo de armazenamento. No período de 180 dias os tratamentos de SVR e CVR se assemelham, não havendo diferença significativa entre os mesmos.

O mesmo comportamento foi observado no tratamento de CVR que manteve praticamente estável o teor de artemisinina. No entanto, o teor de artemisinina não diferiu entre os tratamentos, aos 30 e 120 dias, sem diferença significativa em relação aos ambientes de armazenamento, enquanto que aos 90 e 180 dias, se assemelhou ao SVR. Os tratamentos em temperatura 
ambiente (CVA e SVA), estaticamente apresentaram resultados inferiores aos de temperatura refrigerado (CVR e SVR).

A manutenção e conservação de princípio ativo também foi avaliado no armazenamento de Sphagneticola trilobata em embalagens de vidro, polipropileno e papel metalizado por período de 12 meses, sob condição ambiente $\left(20-25^{\circ} \mathrm{C}\right)$ e refrigerado $\left(5^{\circ} \mathrm{C}\right)$. Os resultados avaliados mostraram que, em condição refrigerada, houve uma maior preservação de tanino do que em condição ambiente. Sob-refrigeração, a concentração de tanino nas embalagens e no período de armazenamento ficou entre 1,10 e $1,64 \%$, com média acima de $1 \%$. A embalagem de papel metalizado preservou melhor a concentração de tanino durante todo o tempo de armazenamento, sendo de 1,34\% (3 meses), 1,13\% (6 meses), $1,35 \%$ (9 meses) e $1,64 \%$ (12 meses). A maior preservação da concentração de tanino (FIDELIS et al., 2005).

\subsection{Quantificação do teor da artemisinina em relação ao tempo de armazenamento}

Verificou-se efeito significativo com relação ao tempo de armazenamento para o teor de artemisinina (Figura 2).

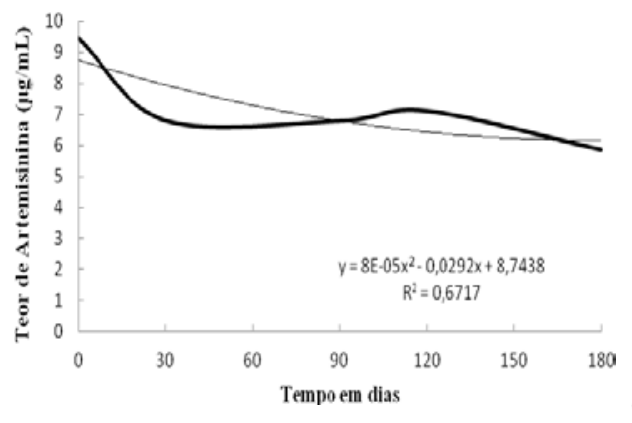

(A)
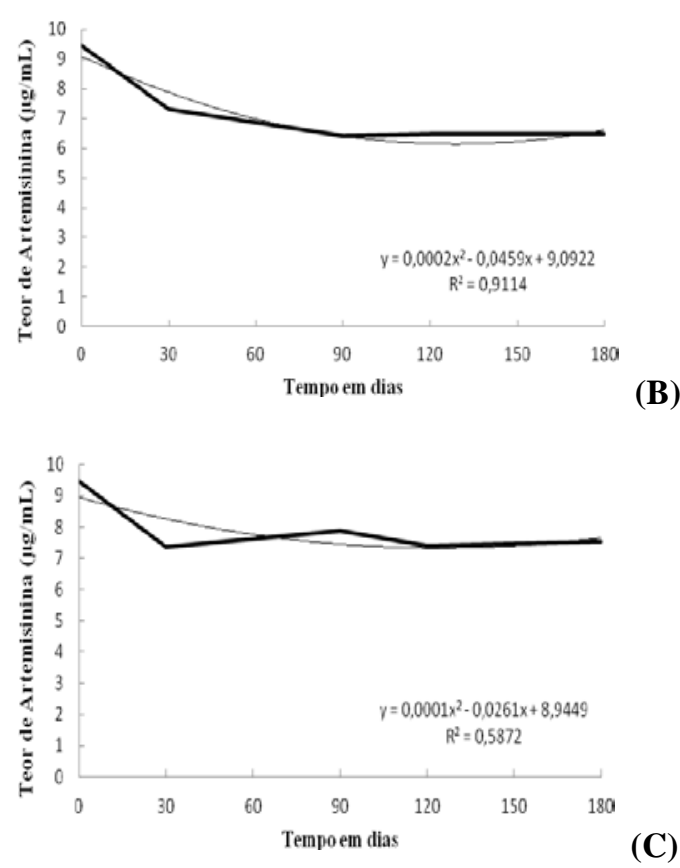

(C)

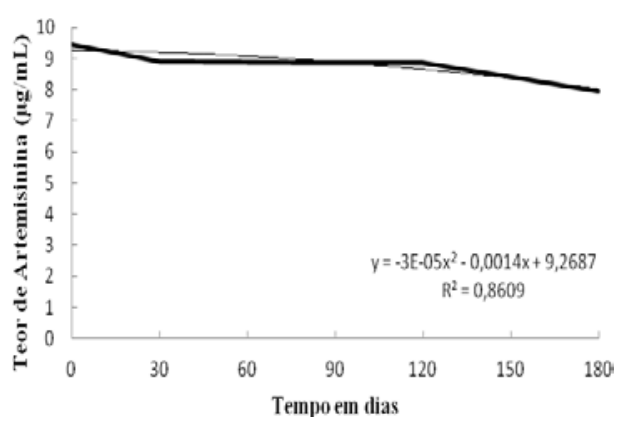

(D)

(A) Com vácuo ambiente, (B) Sem vácuo ambiente, (C) Com vácuo refrigerado, (D) Sem vácuo refrigerado.

\section{Figura 2: Variação do teor de artemisinina durante o tempo de armazenamento.}

O gráfico (A) mostra que houve um declínio no teor de artemisinina nos primeiros 30 dias de armazenamento, mantendo-se estável até os 90 dias, após este período houve aumento do teor com posterior redução. O tratamento sem vácuo ambiente (B) foi o que melhor manteve uma tendência. Houve um declínio consideravel no teor de artemisinina durante os primeiros 30 dias, mantendo-se assim até o final dos 180 dias.

No tratamento, com vácuo refrigerado (C) o teor de artemisinina nos 30 primeiros dias caiu consideravelmente, voltando a subir entre 30 e 90 dias de armazenamento, caindo novamente nos 120 dias e mantendo constante até os 180 dias. Este tratamento foi o menos estável. O tratamento sem vácuo refrigerado (D) mesmo perdendo teor de artemisinina nos primeiros 30 dias manteve-se praticamente constante até 120 dias, aos 150 dias de armazenamento houve um pequeno declínio no teor de artemisinina até os 180 dias.

\section{CONCLUSÃO}

O tratamento mais eficiente para a conservação da droga vegetal foi o sem vácuo refrigerado (SVR). Este tratamento proporcionou a melhor manutenção do teor de artemisinina durante o período de armazenamento, comparado aos demais tratamentos. Houve diferença significativa entre os tratamentos, sendo que aqueles mantidos sob-refrigeração foram os que melhor preservaram o principio ativo de A. аnnua. O fato das amostras terem sido armazenadas em geladeira, fez com que elas mantivessem o teor de água estáveis, ou até mesmo reduzido, fazendo com que a artemisinina sofresse uma degradação mais lenta durante todo o período. Além disso, não se verificou alterações significativas, em termos microbiológicos, entre os tratamentos aplicados. 


\section{REFERÊNCIAS}

VAN DEN BERG, M. E. Plantas medicinais na

Amazônia: contribuição ao seu conhecimento sistemático. 2. ed. Belém: Supercores, 1993. 207 p.

CALIXTO, J. B. Medicamento fitoterápico. In: Yunes, R. A e Calixto, J. B. Plantas medicinais sob a ótica da química orgânica moderna. Santa Catarina: Argus, 2001. p. 277-316.

FARMACOPÉIA brasileira. 4. ed. São Paulo: Atheneu, 1988.

FIDELIS, I. et al. Influência das embalagens e do armazenamento no crescimento microbiológico e na concentração de tanino em Sphagneticola trilobata (L.) PRUSKI. Ceres, São Paulo, v. 52, n. 303, p. 647-657, 2005.

FIGUEIRA, G. M. Mineral nutrition, production, and artemisinin content in Artemisia annua L. Acta Horticulturae, Amherst, USA, v.1, n.426, p. 573-577, 1996.

FIGUEIRA, G. M. et al. Estudo da umidade de equilíbrio de duas espécies de plantas do gênero Phyllanthus após secagem para o armazenamento.

Revista Brasileira de Farmacognosia, Curitiba, v. 14, supl. 01, p. 22-24, 2004.

GUEDES, R. S. et al. Armazenamento de sementes de Myracrodruon urundeuva Fr. All. em diferentes embalagens e ambientes. Revista Brasileira de Plantas Medicinais, Botucatu, v. 14, n. 1, p. 68-75, 2012.

JIN, P.; MADIEH, S.; AUGSBURGER, L. L. The solution and solid state stability and excipient compatibily of parthenolide in feverfew. American Association of Pharmaceutical Scientists, Virginia, v.8, n.4, p. 200-205, 2007.

LACERDA, M. A malária no Brasil. Genebra, Suiça: Medicines for Malaria Venture, 2013. Disponível em: <http://www.mmv.org/>. Acesso em: 19 abr. 2013.

MARCHESE, J. A. et al. Quantificação de artemisinina em Artemisa annua L. - Uma comparação entre as técnicas de cromatografia em camada delgada com detecção densitométrica e cromatografia líquida de alta eficiência com detecção no ultravioleta. Revista

Brasileira de Plantas Medicinais, Brasília, DF, v. 4, n.1, p. 81-87, 2001.

REDDY, D. Malária no Brasil: sociedade Brasileira de Medicina Tropical. Genebra, Suiça: Medicines for Malaria Venture, 2013. Disponível em:

<http://www.mmv.org/>. Acesso em: 19 abr. 2013.
ORGANIZAÇÃO MUNDIAL DA SAÚDE. 10 fatos sobre a malária. Genebra, Suiça, 2013. Disponível em: $<$ http://www. who.int/features/factfiles/malaria/es/>. Acesso em: 18 abr. 2013.

ORGANIZAÇÃO MUNDIAL AS SAÚDE. Relatório Mundial da Malária 2011. Genebra, Suiça, 2011.

Disponível em:

$<$ http://www.paho.org/arg/index.php?option=com_conte nt\&view=article\&id=856\&catid=332:arg.02-prevenciny-control-de-enfermedades\&itemid=226>. Acesso em: 18 abr. 2013.

SOLA, M. C. et al. Manutenção de microrganismos: conservação e viabilidade. Enciclopédia Biosfera, Goiânia, v. 8, n. 14, p. 1398-1418, 2012.

SILVA, F. Avaliação do teor e da composição química do óleo essencial de plantas medicinais submetidas a processos de secagem e armazenamento. 2005. $142 \mathrm{f}$. Dissertação (Doutorado em Tecnologia de Produção Agrícola) - Faculdade de Engenharia Agrícola, Universidade Estadual de Campinas, Campinas, 2005.

SILVA, J. O.; COSTA, P. P.; RECHE, S. H. C. Manutenção de leveduras por congelamento a $-20^{\circ} \mathrm{C}$. Revista Brasileira Análises Clínicas, São Paulo, v. 40, n. 1, p. 73-74, 2008. 